\title{
Toxic metals in the deposited particles from air of the training space of Amir Abad Campus, University of Birjand, 2012
}

\author{
Rezaei MR, $\mathrm{PhD}^{1}$, Sayadi $\mathrm{MH}, \mathrm{PhD}^{1^{*}}$ \\ 1- Assistant Prof., Natural Resource and Environment School, University of Birjand, Birjand, Iran.
}

\begin{abstract}
Received: April 2014, Accepted: July 2014

Background: Composition of dust in the air due to contact with human via inhalation, ingestion and skin absorption will have a large impact on public health. In the learning environments such as universities, many people spend most of their day in contact with the dust. The purpose of this study was to evaluate the concentration of heavy metals; lead, chromium and copper in the training space of the University of Birjand (Faculty of Agriculture and Natural Resources) and examining its ecological risks.

Materials and Methods: This descriptive study evaluated a total of 16 samples where 4 samples pertained to the Faculty of Natural Resources and Environment and 12 samples were from the Faculty of Agriculture. For estimation of the heavy metals; copper, chromium and lead, hydrochloric acid and nitric acid digestion were used. The concentration of heavy metals was measured using an atomic absorption instrument. The regression coefficient was calculated by Ms Excle software.

Results: The results showed that lead (3.414) and copper (14.884) degrees in the official room of the Faculty of Agriculture was more than the Faculty of Natural Resources and Environment while lead (2.575) and chromium (0.187) degrees were higher in the classrooms of the Faculty of Natural Resources. The regression correlation coefficient studies showed that the case study heavy metals had week correlation $\left(\mathrm{R}^{2} ; 0.13\right.$ and 0.20$)$. The pollution index of the element chromium depicted the lowest pollution level and copper had the high pollution levels in some samples.

Conclusions: However, the samples exhibited little ecological risks. Thus, the presence of these elements in dust does not lead to serious health hazards. Nevertheless, further studies at different time periods are worthwhile.
\end{abstract}

Keywords: Dust, Heavy Metals, Risk

\section{Introduction}

Aerosols arise from natural and humaninduced activities and after the passage of required time, with subjection to size and density drop down on the surfaces. On average each individual inhales 10 cubic meters of air into his or her lungs; nevertheless investigating the available compositions in the air particles has a greater importance on the human health. The results of some studies indicate that the air dust contains traces of heavy metals such as lead, chromium, nickel, copper, cadmium, manganese and zinc (1). The results of the researchcarried out on air dust in Turkey demonstrated that the mean concentration of lead in street dust was 9 to 11 times greater than in the soil. In the case of copper and

\footnotetext{
Corresponding author: Mohammadhossein Sayadi, Natural Resource and Environment School, University of Birjand, Birjand, Iran.

Email: mh_sayadi@yahoo.com
} 
cadmium, the mean concentration of these pollutants in street dust doubled in relation to their concentration in the soil and this value in the case of lead was also 9 to 12 times higher (1).

In a study in southern China on the dust deposited in various environments such as school campuses showed that the concentrations of lead, zinc, chromium and cadmium was 80 to 1000,700 to $800,30-50$ and 5-10 mg respectively (2). The study results of Salman Zadeh and colleagues in 2011, which was on the deposition of dust in Tehran showed high concentration of metals; cadmium, zinc, copper, lead, iron, chromium and nickel as compared to the mean concentration of metals found in the earths crust (3) and the study carried out in the city of Zanjan revealed that the mean precipitation of heavy metals in the air dust was 0.082 for zinc, 0.286 for lead, cadmium - 0.018 and chromium -0.009 milligrams per kilogram (4).

These pollutants have the accumulation-able property which leads to exposure of numerous health and environmental issues.

For this reason the heavy metals concentration in urban dust is often used as an indicator of heavy metal pollution of the environment (5). It is noteworthy that in the dust concentration phenomenon of some heavy metals such as lead it triples. Even, the concentration of toxic metals; mercury and arsenic can increase to a considerable level (6).

Heavy metals are considered as toxic metals that are non-biodegradable, thus in optimal values they threaten the biological life (7). Annually 800,000 individuals suffer from premature death due to cardiovascular, respiratory diseases and lung cancer caused by air pollution (8). Also, some of the diseases are caused or exacerbated by the effects of dust. Direct inhalation of the fine particles can cause or aggravate diseases such as bronchitis, emphysema, and silicosis (9).

The presence of heavy metals in the dust leads to increase of these elements in the human body through inhalation, ingestion and skin absorption in a manner that each human being inhales over $100 \mathrm{mg}$ of dust a day into his or her body $(10,11)$. Exposure to the dust containing heavy metals can cause issues such as physical and mental retardation, reduced IQ, poor concentration, headaches, cancer, high blood pressure, general weakness, kidney and liver problems, dys function of the nervous system and interferes with the normal functioning of internal organs or subjects to the aggravated effects of other diseases and in few cases leads to death $(12,11)$. Due to the increasing severity of air pollution, especially particulate matter in recent years and adverse effects of dust containing heavy metals on the health of students, faculties and staffs of the university, the need for the investigation of this project was felt.

The purpose of this study was to evaluate the concentration of heavy metals; lead, chromium and copper in the training space of the University of Birjand (Faculty of Agriculture and Natural Resources) and its ecological risk was also investigated.

\section{Materials and Methods}

The study area was Faculty of Agriculture and Faculty of Natural Resources and Environment, located in Amir Abad campus, University of Birjand. In the Faculty of Agriculture, 1386 students, 52 faculty members and 60 administrative personnel are working and in the Faculty of Natural Resources and Environment, 356 students, 9 faculty members and 19 administrative personnel are functioning. 
This descriptive study evaluated the toxic heavy metals in the training space in 2012. The sampling was carried out from all the places and in locations with similar conditions, the samples were combined wherein, among total 16 samples, 4 samples related to the Faculty of Natural Resources and Environment with an average area of 200 square meters and 12 samples pertained to the Faculty of Agriculture with an average area of 3000 square meters.

The sampling was conducted using a broom or vacuum. Later, the samples were stored in the special bags and immediately transferred to the laboratory. After sieving the samples, dusts with a diameter less than 63 microns were analyzed.

For the measurement of heavy metals; copper, chromium and lead, the hydrochloric and nitric digestion acids were utilized (13). The concentration of heavy metals was measured using an atomic absorption instrument (ContrAA700 of Analytik Jena Company, Germany). Moreover, the regression correlation coefficient was used to determine the coefficient by Ms Excel software at 0.01 levels. To obtain the ecological risk of the case study heavy metals the following formula was used (14).

$$
\begin{array}{cc}
\text { Formula Number } 1 \quad P I=\frac{\mathrm{Cs}}{\mathrm{Bn}} \\
\text { Formula Number } 2 & \mathrm{Er}=\operatorname{Tr} \times \mathrm{PI} \\
\text { Formula Number } 3 & \mathrm{RI}=\sum_{\mathrm{i}=1}^{\mathrm{m}} \mathrm{Er}
\end{array}
$$

Where P1 is pollution factor, $\mathrm{Cs}$ is the concentration of heavy elements in the present study and $\mathrm{Bn}$ is the background values of heavy elements, $\mathrm{Er}$ is the ecological risk of each element and RI represents sum of the ecological risks of the elements. Hakanson proposed Tr level, which is heavy metals toxicity factor and is 5,5 and 2 for copper, lead and chromium respectively.

The ecological risk values obtained were classified into four groups in a manner that the $\mathrm{R} 1$ level lower than 150 is low ecological risk, equal and or more than 150 to 300 medium, equal and or more than 300 to 600 significant risk and if equal or greater than 600 the ecological risk would be too high.

\section{Results}

The mean analysis results of the three pollutant elements; chromium, lead and copper samples were separately studied in the Faculty of Natural Resources and Environment and Agriculture at different places and are shown in Table 1.

Table 1: Mean concentrations of heavy elements $\mathrm{mg}$ in $\mathrm{kg}$ in different places of segregated faculties

\begin{tabular}{lccc|ccc}
\hline \multicolumn{2}{l}{ Faculty Natural Resources and Environment } & \multicolumn{3}{c}{ Faculty of agriculture } \\
\hline Place & $\mathrm{Cr}$ & $\mathrm{Pb}$ & $\mathrm{Cu}$ & $\mathrm{Cr}$ & $\mathrm{Pb}$ & $\mathrm{Cu}$ \\
\hline Official room & 0.583 & 2.012 & 4.754 & 0.380 & 3.414 & 14.884 \\
\hline Classroom & 0.187 & 2.575 & 18.105 & 0.034 & 2.160 & 24.646 \\
\hline Professor room & 0.003 & 6.602 & 7.818 & 0.207 & 2.787 & 19.765 \\
\hline
\end{tabular}

As shown in the Table 1, the level of lead (3.414) and copper (14.884) in the official room of the Faculty of Agriculture was higher than the Faculty of Natural Resources 
and Environment. While the amount of lead (2.575) and chromium (0.187) was higher than in the classrooms of the Faculty of Natural Resources. Level of lead (6.602) in the professor room in the Faculty of Natural Resources and Environment was more whereas the concentration of chromium (0.003) and copper (7.818) were relatively less. Table 1 demonstrates mean concentrations results of three pollutant elements; chromium, lead and copper related to the case study samples in terms of measured locations. As Figure 1 depicts that professor room, classroom and official room showed the highest lead, copper and chromium degrees.

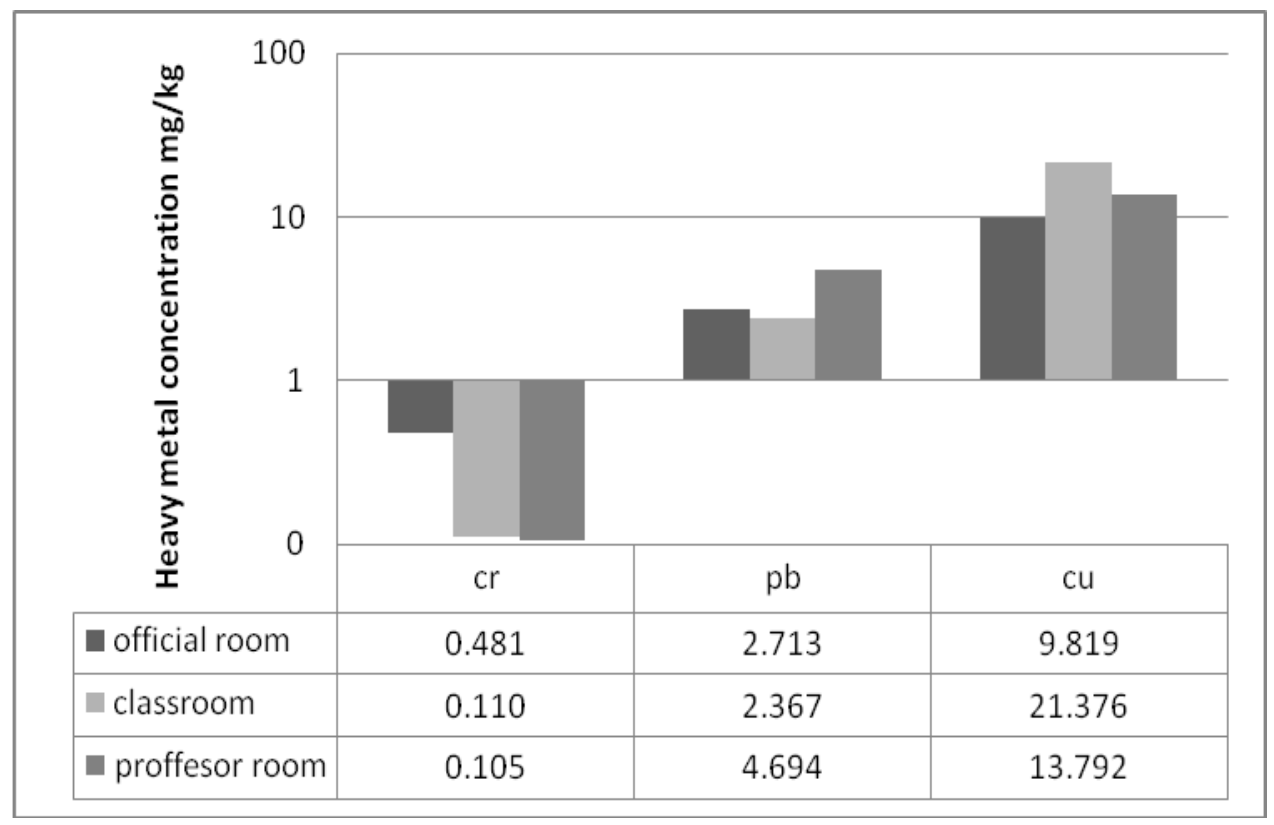

Figure 1. Mean concentrations of chromium, lead and copper in different places

Table 2: Maximum Minimum Mean \pm SD of chromium, lead and copper in 16 samples

\begin{tabular}{cccc}
\hline & $\mathrm{Cr}$ & $\mathrm{Pb}$ & $\mathrm{Cu}$ \\
\hline Mean & 0.232 & 3.258 & 14.996 \\
\hline Max & 0.839 & 9.521 & 41.72 \\
\hline Min & 0.0004 & 0.41 & 3.057 \\
\hline Std & 0.196 & 1.26 & 12.87 \\
\hline
\end{tabular}

Table 2 demonstrates the Maximum Minimum Mean \pm SD of concentrations of three pollutant elements; chromium, lead and copper in the 16 samples of the case study.
The maximum degree of chromium and lead concentrations pertained to the professor room in the Faculty of Agriculture while the maximum degree of copper was derived from the classes in the Faculty of Agriculture.

\section{Discussion}

Table 3 shows the elements concentration degree in the case study in comparison with the other studies. Only, the lead and chromium degrees in Kartazna city of China was lower than the studied samples and even 
the amount of copper in the dusts of Mashhad city was lower than the present study while other cities in Iran and around the world have substantial amounts of heavy metals. Even the concentration of heavy metals in the earth's crust except lead was higher than the present study.

Table-3 Comparison of the mean of existing heavy metals in case study dusts with other parts $\mathrm{mg} / \mathrm{kg}$

\begin{tabular}{lccc}
\hline City & $\mathrm{Cr}$ & $\mathrm{Cu}$ & $\mathrm{Pb}$ \\
\hline Birjand, Iran (case study) & 0.232 & 3.258 & 14.996 \\
\hline Mashhad, Iran (15) & - & 0.69 & 169.65 \\
\hline Tehran, Iran (3) & 33.3 & 222 & 254.4 \\
\hline Kartazna China (16) & 0.02 & - & 2.5 \\
\hline Jordan, Oman (12) & 18.32 & 249.6 & 976 \\
\hline Madrid, Spain (17) & 61 & 188 & 1927 \\
\hline Ottawa, Canada (18) & 59 & 188 & 68 \\
\hline $\begin{array}{l}\text { Mean concentration of } \\
\text { heavy metals in the } \\
\text { earth's crust (19) }\end{array}$ & 100 & 50 & 14 \\
\hline
\end{tabular}

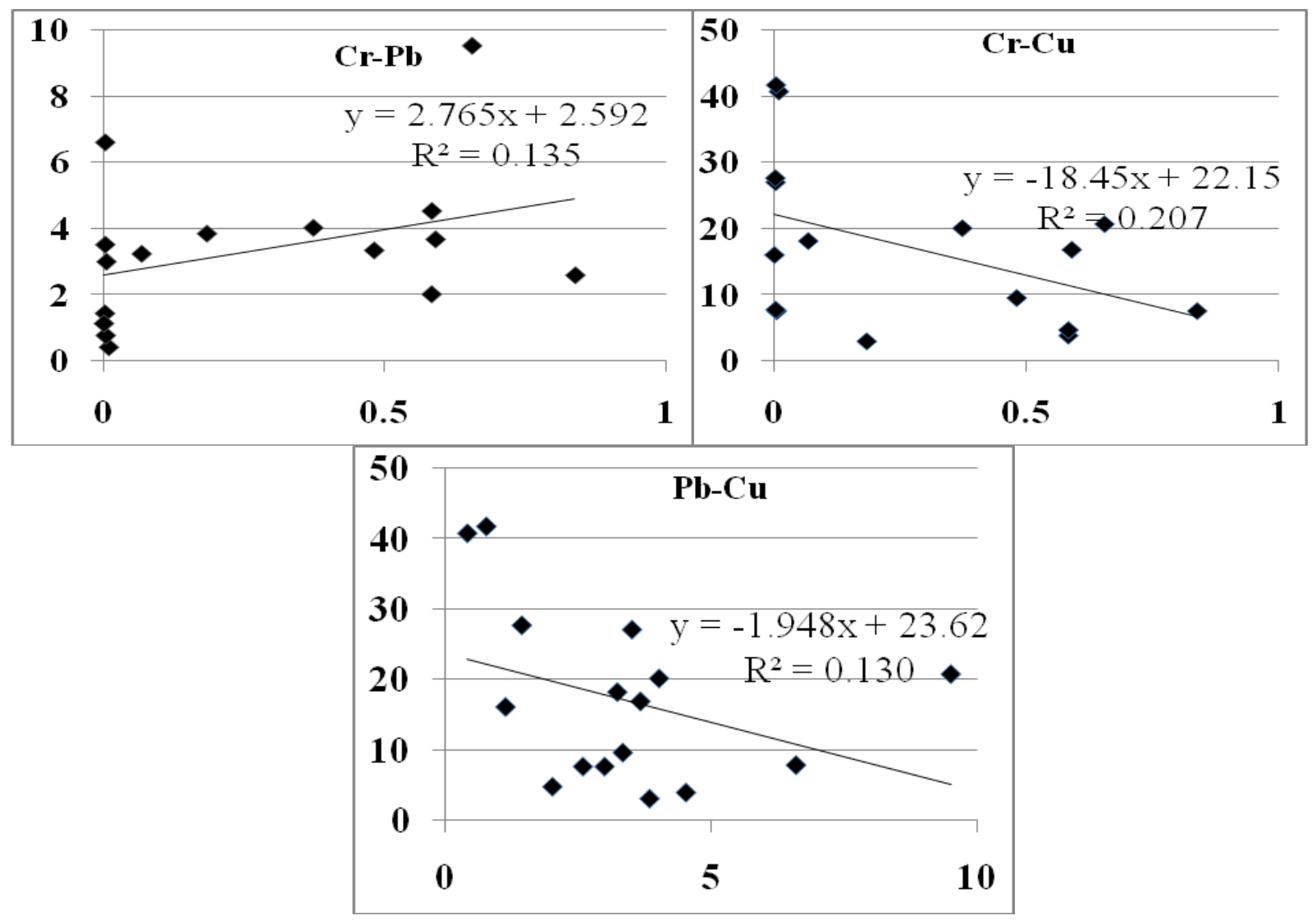

Figure 2. Regression correlation between the heavy elements 


\section{Regression correlation between heavy elements}

As shown in Figure 2 the case study heavy elements possess a relatively weak and positive correlation which indicates that the pollutants are generated from multiple independent sources. Among these elements, chromium and copper $\mathrm{R}^{2}=0.207$ depicted the highest correlation among the elements. A study conducted by Salman Zadeh and colleagues in 2012 in Tehran showed that there is a positive correlation between copper, chromium and lead (3).

In a study conducted in Zanjan, Farahmand Kia et al. (2010) showed a positive correlation 0.61 between lead and chromium (4). Weak correlation coefficient values for case study heavy elements may be due to relatively low concentrations as compared to other studies (Figure 2).

Table 4: Pollution index of the sampled areas

\begin{tabular}{lccc}
\hline \multicolumn{4}{c}{ Heavy elements pollution index in the Faculty of Natural Resources and Environment } \\
\hline Place & $\mathbf{C r}$ & $\mathbf{P b}$ & $\mathbf{C u}$ \\
\hline Official room & 0.056 & 0.389 & 0.494 \\
\hline Classroom 1 & 0.000 & 0.218 & 1.672 \\
\hline Classroom 2 & Heavy elements pollution index in the & Faculty of Agriculture & 2.093 \\
\hline Professor room & $\mathbf{C r}$ & 0.778 & $\mathbf{P}$ \\
\hline & 0.000 & $\mathbf{P b}$ & $\mathbf{C u}$ \\
\hline Place & 0.057 & 0.710 & 1.754 \\
\hline Official room 1 & 0.046 & 0.645 & 0.998 \\
\hline Official room 2 & 0.007 & 0.626 & 1.890 \\
\hline Official room 3 & 0.000 & 0.579 & 0.791 \\
\hline Official room 4 & 0.018 & 0.743 & 0.318 \\
\hline Classroom 1 & 0.000 & 0.679 & 2.813 \\
\hline Classroom 2 & 0.000 & 0.277 & 2.877 \\
\hline Classroom 3 & 0.001 & 0.079 & 4.236 \\
\hline Classroom 4 & 0.000 & 0.148 & 4.337 \\
\hline Classroom 5 & 0.063 & 1.842 & 2.156 \\
\hline Classroom 6 & 0.056 & 0.876 & 0.407 \\
\hline Professor room 1 & 0.081 & 0.500 & 0.792 \\
\hline Professor room 2 & 0.057 & 0.710 & 1.754 \\
\hline Professor room 3 & & 1.277 \\
\hline
\end{tabular}

\section{Pollution Index PI}

In order to identify the sources of pollutants in the case study, the pollution index factor was used. As shown in the Formula 1 for its calculation there is a need of elements background degree. In the different studies conducted worldwide, background concentration of heavy metals is considered based on the previous studies. (20-23). Even in few studies the concentration of heavy metals in the earth's crust is used (24). Considering that the heavy metals evaluations in the dust of University of Birjand and even the city of Birjand has been studied for the first time and due to lack of 
information, a part of the field from the west of Tehran city was undertaken (25). The pollution index classified as below is presented in the Table 4.

$\mathrm{PI} \leq 1 \quad$ Low pollution level $1<\mathrm{PI} \leq 3$ Moderate pollution level

PI $>3$ High pollution level

As shown in Table 4, considering element chromium, pollution level in all the sampled areas was low. But the professor's rooms in the Faculty of Agriculture and Natural Resources and Environment in terms of element lead had a moderate pollution level and in the other areas was low. But the copper pollution level in the classes of Faculty of Natural Resources and Environment was moderate, while the classrooms 5 and 6 of the Faculty of Agriculture exhibited high pollution levels and the classrooms 3 and 4, official rooms 1 and 3 and professor room 1 demonstrated moderate pollution level.

\section{Ecological risk}

Using Formula numbers 2 and 3, Er and RI values were calculated and the results are presented in the Table 5. As shown in Table 5 effectually all the sampled areas showed a little ecological risk. The highest ecological risk was associated with classroom number 6 in the Faculty of Agriculture and the lowest risk belonged to the official room of the Faculty of Natural Resources and Environment.

Table 5: Ecological Risk Index of heavy elements

\begin{tabular}{|c|c|c|c|c|c|}
\hline $\begin{array}{c}\text { Faculty of } \\
\text { Natural Resources and Environment }\end{array}$ & $\operatorname{Er} \mathrm{Cr}$ & $\operatorname{Er} \mathbf{P b}$ & $\mathrm{Er} \mathrm{Cu}$ & RI & Ecological risk \\
\hline Official room & 0.11 & 1.95 & 2.47 & 4.53 & Low \\
\hline Classroom 1 & 0.00 & 1.09 & 8.36 & 9.45 & Low \\
\hline Classroom 2 & 0.07 & 3.89 & 10.46 & 14.42 & Low \\
\hline Professor room & 0.00 & 6.38 & 4.06 & 10.45 & Low \\
\hline Faculty of Agriculture & $\mathrm{ErCr}$ & $\mathrm{Er} \mathrm{Pb}$ & $\mathrm{Er} \mathrm{Cu}$ & RI & Ecological risk \\
\hline Official room 1 & 0.11 & 3.55 & 8.77 & 12.43 & Low \\
\hline Official room 2 & 0.09 & 3.23 & 4.99 & 8.31 & Low \\
\hline Official room 3 & 0.01 & 3.13 & 9.45 & 12.59 & Low \\
\hline Classroom 1 & 0.00 & 2.90 & 3.96 & 6.85 & Low \\
\hline Classroom 2 & 0.04 & 3.72 & 1.59 & 5.34 & Low \\
\hline Classroom 3 & 0.00 & 3.40 & 14.06 & 17.46 & Low \\
\hline Classroom 4 & 0.00 & 1.39 & 14.39 & 15.77 & Low \\
\hline Classroom 5 & 0.00 & 0.40 & 21.18 & 21.58 & Low \\
\hline Classroom 6 & 0.00 & 0.74 & 21.68 & 22.43 & Low \\
\hline Professor room 1 & 0.13 & 9.21 & 10.78 & 20.11 & Low \\
\hline Professor room 2 & 0.11 & 4.38 & 2.04 & 6.53 & Low \\
\hline Professor room 3 & 0.16 & 2.50 & 3.96 & 6.62 & Low \\
\hline
\end{tabular}




\section{Conclusion}

In the present study, the concentration of three heavy elements; lead, copper and chromium in 16 samples of dust deposited in different locations in the Faculty of Agriculture and Faculty of Natural Resources and Environment were evaluated. The pollution index and ecological risk associated with the heavy metals were also determined. Considering the conducted calculations and analysis the pollution index of element chromium had the lowest pollution level and lead had the high pollution level in few samples. Considering ecological risk calculations, all the stations demonstrated a little risk. Thus it can be safely concluded that the presence of these heavy elements in the dust do not cause serious health hazards. However, further studies at different time periods seem necessary.

\section{Acknowledgments}

This study was funded by the Research Council of University of Birjand which as a Research Project was conducted in 2013. Authors appreciate the authorities of Research Council and Faculty of Natural Resources and Environment, University of Birjand, due to their sincere cooperation. We also like to thank Dr. Mahavash F. Kavian for editing the paper.

\section{Conflict of interest: Non declared}

\section{References}

1. Sezgin N, Ozcan HK, Demir G, Nemlioglu S, Bayat C. Determination of heavy metal concentration in street dusts in Istanbul E5highway. Environ Int 2004; 29(7):979-85.

2. Leung AO, Duzgoren-Aydin NS, Cheung KC , Wong MH. Heavy metals concentrations of surface dust from e-waste recycling and its human health implications in southeast china, Environ Sci Technol 2008; 42(7):2674-80.

3. Salmanzadeh M, Saeedi M, Nabi Bidhendi G. Heavy metals pollution in street dusts of Tehran and their ecological risk assessment. Journal of Environmental Studies 2012; 38(61):4-6.

4. Farahmand kia Z, Mehrasbi MR, Sekhawatju MS, Hasanalizadeh ASH, Ramezanzadeh Z. Study of heavy metals in the atmospheric deposition in Zanjan, Iran. Iranian Journal of Health and Environment 2010; 2(4):240-9.

5. Li X, Poon CS, Liu PS. Heavy metal contamination of urban soils and street dusts in Hong Kong. Appl Geochem 2001; 16(1112):1361-8.

6. Nadafi K. Air pollution with emphasis on dust and health effects and environmental. Paper presented at: Twelfth National Conference on Environmental Health; 2009 November; Tehran, Iran.

7. Tong ST, Lam KC. Home sweet home? A case study of household dust contamination in Hong Kong. Sci Total Environ 2000; 256(2-3):115-23.

8. Curtis L, Rea W, Smith-Willis P, Fenyves E, Pan Y. Advers health effects of outdoor air pollutants. Environ Int 2006; 32(6):815-30.

9. Goudie AS, Middleton NJ (2006). Desert dust in the global system: with 41 tables. Berlin \& New York: Heidelberg \& Springer. PP:287.

10. Sayadi MH, Torabi S. Geochemistry of soil and human health: A review. Pollution Research 2009; 28(2):257-62.

11. Murgueytio AM, Evans RG, Sterling D, Serrano F, Roberts D. Behaviors and blood lead levels of children in a lead-mining area and a comparison community. Journal of Environmental Health 1998; 60(6):14-20.

12. Jiries A. Vehicular Contamination of Dust in Amman, Jordan. Environmentalist 2003; 23(3):205-10.

13. Burt R. Soil Survey Laboratory Methods Manual. Lincoln, Nebraska: United States Department of Agriculture, Natural Resources Conservation Service; 2004 Feb. Version 4.0. Soil Survey Investigation Report. No; 42.

14. Hakanson L. An ecological risk index for aquatic pollution control. a sedimentological approach. Water Res 1980; 14:975-1001.

15. Behravesh F, Mahmoodi MH, Ghasemzadeh F, Avazmoghadam S. The contamination of heavy metals in urban soils and traffic dust in Mashhad. Paper presented at: The First Geological Congress of Iranian plateau; 2013 March 1-2; Kerman, Iran.

16. Moreno-Grau S, Cascales-Pujalte JA, Martinez-Garcia MJ, Angosto J, Moreno J, Bayo J, et al. Relationship between levels of lead, cadmium, zinc and copper in soil and settleable particulate matter in Cartagena 
(Spain). Water Air Soil Pollut 2002; 137(14):365-83.

17. De Miguel E, Llamas JF, Chacón E, Berg T, Larssen S, Røyset O, Vadset M. Origin and patterns of distribution of trace elements in street dust: Unleaded petrol and urban lead. Atmos Environ 1997; 31(17):2733-40.

18. Rasmussen PE, Subramanian KS, Jessiman BJ. A multi-element profile of housedust in relation to exterior dust and soils in the city of Ottawa. Canada. Sci Total Environ 2001; 267(1-3):125-40.

19. Karbassi AR, Nabi-Bidhendi GHR, Bayati I. Environmental geochemistry of heavy metals in a sediment core off Bushehr Persian Gulf. Iranian J Environ Health Sci Eng 2005; 2(4):225-60.

20. Sayadi MH, Sayyed MR, Kumar S. Shortterm accumulative signatures of heavy metals in river bed sediments in the industrial area, Tehran Iran. Environ Monit Assess 2010; 162(1-4):465-73.

21. Sayadi MH, Sayyed MRG. Comparative assessment of baseline concentration of the heavy metals in the soils of Tehran (Iran) with the comprisable reference data. Environ Earth Sci 2011; 63(6):1179-88.

22. Sayadi MH, Rezaei MR. Impact of land use on the distribution of toxic metals in surface soils in Birjand city, Iran. Proceedings of the International Academy of Ecology \& Environmen 2014; 4(1):18-29.

23. Manasreh WA. Assessment of trace metals in street dust of mutah city, Kurak, Jordan. Carpathian Journal of Earth and Environmental Sciences 2010; 5(1):5-12.

24. Kartal S, Aydin Z, Takalioglu S. Fractionation of metals in street sediment samples by using the BCR sequential extraction procedure and multivariate statistical elucidation of the data. J Hazard Mater 2006; 132(1):80-9.

25. Sayyed MRG, Sayadi MH. Variations in the heavy metal accumulations within the surface soils from the chitgar industrial area of Tehran. International Academy of Ecology and Environmental Sciences 2011; 1(1):3646. 